\title{
La religiosidad en el espacio público a partir de Ortega y Gasset
}

Religiosity in the public sphere from the perspective of Ortega y Gasset

\section{ÁNGEL PERIS}

Facultad de Teología San Vicente Ferrer

Departamento de Filosofía

46111 Rocafort, Valencia (España)

alperis@colegioceu.es

Abstract: Ortega dealt with the topic of religion from the perspective of a very personal kind of religiosity, and he defended the secular state from this perspective. For this reason, it is interesting to consider how Ortega's view of religion would respond to two questions: what is the place of religion in the public sphere of a plural society, and what can religion contribute to the secular state in response to the demands of a democratic society that does not resign itself to being indifferent to the religious fact.

Keywords: Ortega y Gasset, religiosity, secular state.
Resumen: Ortega trató el tema religioso desde un modo muy personal de religiosidad y defendió el Estado Laico. Por eso pensamos que puede ser interesante plantearnos la visión que Ortega propone de la religión intentando responder a dos cuestiones: qué lugar debe ocupar la religión en el espacio público de una sociedad plural y qué puede aportar la religión en el Estado laico para responder a las exigencias de una sociedad democrática que no se conforme con ser indiferente al hecho religioso.

Palabras clave: Ortega y Gasset, religiosidad, estado laico. 


\section{INTRODUCCIÓN Y ESTADO DE LA CUESTIÓN}

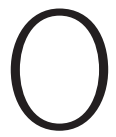

rtega nunca trató el tema religioso de forma sistemática aunque sus referencias y alusiones en este sentido fueron muchas. Pese a eso, el problema religioso en Ortega fue objeto de grandes disputas a partir de los años $40^{1} \mathrm{y}$ se recrudecieron con las campañas institucionales de propaganda que intentaban o bien capitalizar políticamente su regreso del exilio como un gesto de adhesión o bien neutralizar, a la vez que controlar, cualquier influencia del filósofo. Una parte del pensamiento católico consideraba el "acatolicismo" de Ortega como "envenenador[es] de las mentes juveniles" ${ }^{2}$, incompatible con la doctrina católica ${ }^{3}$. La crítica no sólo buscaba su desprestigio sino, según relata José L. Abellán ${ }^{4}$, el intento de incluirle en el Índice de libros prohibidos de la Iglesia. En ese contexto hay que enmarcar la estéril disputa que se produjo tras su muerte sobre la pretendida conversión religiosa según relataba el diario $Y a^{5}$. En la defensa del orteguismo intervinieron entre otros, dos discípulos confesados católicos: M. García Morente y J. Marías, además del mismo Laín Entralgo entonces rector de la Universidad Complutense de Madrid y J. L. López Aranguren ${ }^{6}$. Eran los tiempos de la España de posguerra en la que los dos bandos enfrentados encontraban en Ortega una figura incómoda ${ }^{7}$.

1. A. MaRTín, Ortega y Unamuno en la España de Franco. El debate intelectual durante los años cuarenta y cincuenta (Encuentro, Madrid, 2009).

2. P. LaÍn Entralgo, Descargo de conciencia (1930-1960) (Barral, Barcelona, 1976) 408.

3. J. IRIARTE, Ortega y Gasset su persona y su doctrina (Razón y Fe, Madrid, 1942); J. SÁNCHEZ, Fosé Ortega y Gasset. Pensamiento y trayectoria (Universidad Iberoamericana, 1943); S. RAMíREZ, La filosofía de Ortega y Gasset (Herder, Madrid, 1958).

4. J. L. AbELLÁN, Ortega y Gasset y los orígenes de la transición democrática (Espasa, Madrid, 2000) 211.

5. Ya, 19 de octubre de $1955 ;$ J. L. AbELLÁN, op. cit,. recoge en carta a $A B C$ publicada en 1975, la carta de sus hijos al ministro de Educación Nacional don Joaquín Ruiz Jiménez pocos días después de su muerte; G. Morán, El maestro en el erial (Tusquets, Barcelona,1998) 51.

6. J. MARÍAS, Ortega y tres antípodas. Un ejemplo de intriga intelectual (Revista de Occidente, Madrid, 1950); P. LAÍN, Los católicos y Ortega, "Cuadernos Hispanoamericanos"101 (1958); y J. L. López, La ética de Ortega, OC, (Trotta, Madrid, 1992) II, 506.

7. F. LóPEZ, Ética y Política. En torno al pensamiento de 7. Ortega y Gasset (PPU, Barcelona, 1985) xxii-xxv. 
Quizá por eso, el tratamiento que hacen sobre el tema los estudios sistemáticos más actuales ha sido puntual ${ }^{8}$. El propósito de este trabajo no guarda relación con esa polémica. No intenta revisar las ideas religiosas, ni especialmente católicas, de Ortega en sentido fuerte: esto es, su idea de Dios y del cristianismo, su concepción del pecado original o de la confesión como hace, por ejemplo, $M^{a}$ Pilar Ramiro9, ni tampoco pretende encontrar "entrelíneas", una interpretación que pudiera afianzar o dejar ver un pensamiento católico ${ }^{10}$. Aunque como advierte Ciriaco Morón frente a los integristas que consideraron el pensamiento de Ortega como baladí o peligroso: “...la teología católica más moderna encuentra bases preciosas en la sustancia de la filosofía orteguiana"11. En general, como afirma Luis M. Pino ${ }^{12}$, en la utilización que hace Ortega de las imágenes y figuras religiosas dista mucho de la que cree un cristiano. Sin embargo, su estudio, aunque útil como síntesis de textos y aportaciones de Ortega, carece del estudio en profundidad que permita contextualizar sus aportaciones.

El objetivo de este trabajo es, contribuyendo a rellenar ese hueco, revisar las ideas religiosas de Ortega para mostrar cómo surge una forma de religiosidad no exclusivamente creyente que puede ocupar un lugar en la racionalidad pública, al menos en el marco de la razón vital ${ }^{13}$. Por eso pensamos que ésta puede ser una cuestión interesante para alumbrar en nuestros días el diálogo sobre el lugar que puede ocupar la religión en el espacio público de una sociedad plural. Una sociedad democrática que no se conforme con ser indiferente al

8. P. Cerezo, La voluntad de aventura (Ariel, Madrid,1984) 102-109; C. MORÓN, El sistema de Ortega (Alcalá, Madrid, 1968) 417-438.

9. Ma. P. Ramiro, Dios y Cristianismo en Ortega y Gasset (Universidad Complutense, Madrid, 2003).

10. D. NATAL, Ortega y la religión. Nueva lectura (Universidad de Valladolid, Valladolid, 1997).

11. C. Morón, op. cit., 8. Y especialmente: "Filosofía orteguiana y Teología católica", 417-438.

12. L. M. PINO, La religión en Ortega y Gasset (Ediciones del Orto, Madrid, 2000) 16.

13. J. J. GARRIDO, La religiosidad del respeto, en Evangelio y cultura (Facultad de Teología San Vicente Ferrer, Valencia, 2011) 235-246; J. ConiLl, De la religión de la vida a la religión personal en Ortega y Zubiri, "The Xavier Zubiri Review” 8 (2006) 93-101. 
hecho religioso considerándolo como algo íntimo, sino que intente un nuevo concepto de razón pública que, más que simplemente "tolerar", incluya lo religioso, sin dejar por ello de ser racional y laica.

Ortega, según relata su hijo ${ }^{14}$, había perdido desde joven la fe y según él mismo manifestó no era católico ${ }^{15}$, quiso mantener acatólicamente sus celebraciones civiles. Se trata pues de un pensador que se manifestó públicamente muy crítico con el cristianismo, sobre todo en los primeros escritos y de forma más moderada y abierta después, a la vez que defendió el Estado laico en los debates de República. Para nuestra cuestión, no es importante la filiación religiosa de Ortega. O al contrario, el valor y el lugar significativo que encuentre de la religiosidad en la sociedad puede tener más importancia precisamente por no provenir de alguien de quien ya se espera a priori una respuesta dada.

La interpretación que hace Ortega de la cuestión religiosa y del cristianismo ha evolucionado con el resto de sus posiciones filosóficas y en relación a su circunstancia que fue siempre el problema de España ${ }^{16}$. Comenzaremos revisando sus ideas religiosas relacionándolas con la evolución de su pensamiento para intentar responder a la cuestión sobre qué significa la religiosidad y qué puede aportar a la sociedad, para finalmente, ver cómo encaja en su defensa del Estado Laico.

\section{NUEVOS ESPACIOS DE RELIGIOSIDAD}

a) La sustitución de la religión por la cultura y la emoción religiosa del respeto en los primeros escritos

El punto de partida para situar el pensamiento político de Ortega es el liberalismo ${ }^{17}$. Una concepción de la libertad basada en la idea de

14. J. Ortega Espotorno, Los Ortega (Taurus, Madrid, 2002) 413.

15. J. ORTEGA, En torno a Galileo, VI, 496 [las citas de textos de OrTEGA, corresponden a la edición de Obras Completas, 10 vols. (Taurus, Madrid, 2004-2010). Se indicará volumen y página]. J. ORTEGA, Rectificación de la República, IV, 847.

16. A. Moreno, Ortega y Gasset: religión y problema de España, "Pensamiento" 253/67 (2011) 459-486.

17. Á. PERIs, El liberalismo de Ortega más allá del individualismo, "Revista de Estudios Orteguianos" 6 (2003) 169-198. 
esperanza $^{18}$. El liberalismo de Ortega no es sólo una ideología, sino que hunde sus raíces en el centro de su concepto de hombre y de su visión histórica de la sociedad. El atributo esencial de la vida, entendida como realidad radical, es la necesidad de decidir en cada instante lo que el hombre va a ser, escoger entre las diversas posibilidades que se le presentan o que imagina. Esta dimensión futuriza que toma la vida como quehacer supondrá para Ortega una apuesta incondicional por la libertad y el liberalismo. Por eso, concluye, el hombre es "por fuerza libre"19 una "ontología de la libertad"20. Pero entonces, la creación de ideales políticos no es cualquier creación, no todo vale por igual, porque la exigencia de la circunstancia y de la idea de libertad, en sí misma, es fuente absoluta de valor político. "No hay más que un progreso, el progreso en libertad" ${ }^{21}$. No es el liberalismo de los liberales del XIX. Es una política de la libertad que hay que tomarse el trabajo de pensar en cada momento de la historia y de acuerdo a la realidad social. Pero siempre con un objetivo explícito: la promoción de lo mejor de cada hombre: un instrumento lento y concienzudo capaz de transformar el carácter español ${ }^{22}$.

La primera consecuencia de esta visión social es que para Ortega el problema político nacional es pedagógico. Durante la primera etapa de sus escritos, en los que está más presente la influencia neokantiana y nietzscheana, justifica su tesis sobre la educación política en el proceso de socialización. Para Natorp, el ideal ético sólo podía realizarse dentro de la comunidad a través de la influencia educativa de la sociedad. El ciudadano es el resultado del influjo de una cultura, es decir, de un conjunto ideales que constituyen el ethos de un pueblo. Para Ortega, era necesario acrecentar el peso moral de la so-

18. J. L. LÓPEZ, op. cit., 524; C. MORÓN, op. cit., 188; P. LAÍN, La espera y la esperanza (Alianza, Madrid, 1984) y también Creer esperar, amar (Galaxia Gutenberg, Barcelona, 1993) 147 y ss.

19. J. ORTEGA, Historia como sistema, VI, 66.

20. I. SÁncheZ, El liberalismo de Ortega y Gasset, "Revista de Occidente" 108 (1990) 72. P. Cerezo, Razón vital y liberalismo en Ortega, "Revista de Occidente" 120 (1991) 34.

21. J. ORTEGA, La conservación de la cultura, I, 149.

22. V. CACHO, Los intelectuales y la política. Perfil público de Ortega y Gasset (Biblioteca Nueva, Madrid, 2000) 90 y ss. 
ciedad, pero la virtud moral y la justicia política están en relación con el conocimiento científico. "Cultura es el cultivo del entendimiento humano en cada hombre, de su moralidad, de sus sentimientos"23.

Se trataba de educar la virtud pública. La renovación del país no podía venir de predicar la virtud, de forma más o menos espiritual y enfática que caracterizaba las formas de educación social y religiosa anterior. Frente al "patriotismo teológico" 24 que mide el genio de los pueblos por la altura de la fe, la nueva perspectiva exige medirlo por el engrandecimiento de la sabiduría y la virtud. Según piensa Ortega, el catolicismo español había representado un freno para el desarrollo de la cultura. Así lo expresa en una carta personal: "Si hablo siempre con tanto enojo del catolicismo es porque representa para mí, en primer lugar, la absoluta contradicción de cuanto yo llamo cultura, humanidad, virtud y en segundo, porque él y acaso nada más ha sido el esquilador de nuestra raza..."25.

El cristianismo es visto como una fuerza que impulsó el mundo con su influencia espiritual, por tanto, como una fuerza positiva históricamente, pero que ha cumplido su momento, necesita diluirse y purificar su contenido en la ciencia moderna. El hombre necesita siempre un repertorio de ideas que proporcionen una interpretación explicativa y esclarecedora sobre la existencia, destacando así su función hermenéutica. Para Ortega la religión había constituido durante siglos esa tarea, el poder espiritual que unificaba una cosmovisión de sentido compartida. Dios era el poder socializador, constructor de comunidad, pero ha cumplido su tiempo ${ }^{26}$. Para Ortega la convicción religiosa era "primitiva", puramente "sentimental"27 y por eso tras la Ilustración ya no fue capaz de integrar a los ciudadanos, la fe habría dejado de ser vigente en las minorías europeas. La función de aclarar el sentido y la orientación de la realidad, que originalmente era desempañada por la idea de Dios se habría secu-

23. J. ORTEGA, La ciencia y la religión como problemas políticos, VII, 135.

24. J. ORTEGA, Sobre el proceso Rull, I, 160-161.

25. J. Ortega (ed.), Cartas de un joven español 1891-1908 (El Arquero, Madrid, 1991) 566.

26. J. ORTEGA, La cuestión moral, I, 211.

27. J. ORTEGA, La ciencia y la religión como problemas políticos, VII, 135. 
larizado $^{28}$ y habría pasado a ser desempeñada por la cultura ${ }^{29}$ y la ciencia. La moral, la ciencia, el arte, la religión, la política, ya no son cuestiones personales, sino de responsabilidad intelectual ${ }^{30}$. Frente a lo que defendiera Dilthey ${ }^{31}$, las distintas formas de interpretación no son "posibilidades permanentes" a las que siempre es posible volver indistintamente, sino que constituyen una secuencia inexorable en cuya cumbre se encuentra la filosofía, una interpretación sobre la existencia que aparece cuando se desvanecen por sí mismas las creencias anteriores. "Las religiones, como sustancias transferibles y expansivas, han fenecido para siempre" 32 .

Y en sus escritos de socialismo idealista todavía hace más hincapié en esta labor de la cultura. Frente a la virtud religiosa, Ortega propone el socialismo como virtud moral: "es la veracidad científica, es la justicia"33. En un sentido "sansimoniano", piensa que una nueva forma de convicción va ganando progresivamente terreno: la convicción científica de la naturaleza y de la política. "Socialismo y humanidad son dos voces sinónimas ... Para mí, socialismo es cultura...El socialismo es el constructor de la gran paz sobre la tierra" ${ }^{34}$. En este sentido se encuentran afirmaciones en las que Ortega parece hacer suyo el pensamiento de Renan: "Dios es la cultura..." 35 . De manera semejante a como lo hizo Feuerbach, la idea de Dios es una exaltación y proyección inconsciente de las fuerzas interiores del espíritu humano llevadas a categoría de ideal. Un hombre que descubre en sí la necesidad de sacrificarse por el interés común o la necesidad de alcanzar la verdad, terminaría atribuyendo este impulso a la acción de fuerzas superiores al hombre mismo ${ }^{36}$.

28. M. Pallottini, Liberalismo y democracia en Ortega y Gasset, "Revista de Filosofía" 13/8 (1995) 133; C. Morón, op. cit., 67.

29. J. OrTega, Meditaciones del Quijote, I, 788.

30. J. ORTEGA, Unamuno y Europa, fábula, I, 259.

31. J. ORTEGA, La idea de principio en Leibniz, IX, 1154-1155.

32. J. ORTEGA, Sobre una apología de la inexactitud, I, 224.

33. J. ORTEGA, La ciencia y la religión como problemas políticos, VII, 126.

34. J. ORTEGA, Ibidem, 131.

35. J. ORTEGA, La teología de Renan, I, 334.

36. J. Ortega, Meditación del Escorial, II, 659. 
Pero entonces hay que prestar atención a que Ortega va más allá de la mera proyección, porque por medio de esta dimensión religiosa está situando esta fuerza interior, estrictamente intramundana, en un plano de valoración que la convierte en algo sagrado: "Dios es lo mejor del hombre, lo que le enorgullece, lo que intensifica su energía espiritual, la herencia científica y moral acumulada lentamente en la Historia" ${ }^{37}$. El hombre encuentra en sí mismo, en el espíritu de verdad o de justicia conquistado como herencia a lo largo de la historia, algo que le eleva, le produce admiración y lo hace único, algo que requiere un cuidado especial. Es, por tanto, algo más que la humanización de Dios, es, sobre todo, la sacralización del hombre de la que emana la misma esperanza.

Pero junto con este imperativo de la virtud científica, Ortega plantea un concepto más amplio de la religiosidad que tiene su origen en la crítica al cientificismo de la Modernidad ${ }^{38}$. La religiosidad es la actitud que hace evidente la búsqueda de un sentido o un significado de las cosas que no es expresable exclusivamente conforme a la mentalidad científica. Por eso no acepta el desprecio y la renuncia a lo religioso como si se tratara de un prejuicio: "Pues si hay un mundo de superficies... y un mundo de bellezas..., hay también un mundo, más allá, de realidades religiosas" 39 . Ortega considera que la religiosidad expresa una dimensión humana esencial que consiste en ver más allá de las cosas en su inmediato mostrarse. Ni la ciencia positiva tiene la última palabra, ni tampoco la religión que se encierra en sus dogmas e impide la investigación de la verdad al considerarse una verdad definitiva.

Decir que no existen los dioses es decir que las cosas no tienen, además de su constitución material, el aroma, el nimbo de una significación ideal, de un sentido. Es decir, que la vida no tiene sentido, ... ${ }^{40}$.

37. J. ORTEGA, La teología de Renan, I, 334.

38. J. J. GARRIDO, op. cit., 238.

39. J. Ortega, Sobre el Santo, II, 20.

40. J. Ortega, Tres cuadros del vino, II, 199. 
$\mathrm{Al}$ mismo tiempo, encontramos en Ortega lo que podemos llamar una concepción vitalista de la religión ${ }^{41}$. "La cultura nace de la emoción religiosa"42. Y añadirá Ortega, recordando a Goethe, que los hombres son productivos mientras participan de la emoción religiosa entendida como "esfuerzo anticipador de lo superfluo". "De la mera curiosidad, del frívolo diletantismo no ha surgido nunca nada robusto ni orgánico"43. La emoción religiosa, para Ortega, es una actitud de respeto hacia la vida de la que nace la verdadera cultura: tomarse la vida en serio. "Todo hombre que piense: "La vida es una cosa seria" es un hombre religioso" 44 . Por eso, "La verdadera irreligiosidad es la falta de respeto hacia lo que hay encima de nosotros y a nuestro lado, y más abajo. La frivolidad es la impiedad..." ${ }^{45}$. En consecuencia, la actitud religiosa que describe Ortega no es la que concibe la religión como huida del mundo. Más bien justo al contrario, la religiosidad se expresa como amor por la realidad ${ }^{46}$, el respeto del que nace la admiración, necesidad de comprensión, el mundo como problema que es preciso resolver, del que no se puede escapar y que mide el grado de autenticidad y plenitud vital.

De la emoción religiosa nacerá la cultura, entendida como búsqueda paulatina de la solución del problema del mundo, en las que ciencia y religión serán "dos hermanas concebidas en aquella matriz original del respeto" ${ }^{47}$. Una concepción de la cultura que no le impide reconocer que más allá de la mirada científica de la realidad hay un sentido que se ha intentado expresar de distintas formas, todas valiosas, entre ellas la manera religiosa. Continuando este planteamiento orteguiano, Conill ${ }^{48}$ se pregunta en consecuencia, si en el fondo, fe y ciencia no surgen en su raíz de la libertad. Ciencia y religión como dos interpretaciones funcionales de la realización de la vida que muestran perspectivas de la verdad.

41. J. CONILL, op. cit., 93-101.

42. J. ORTEGA Sobre el Santo, II, 25.

43. J. ORTEGA, Ibidem, II, 23.

44. J. ORTEGA, Ibidem, II, 24.

45. J. ORTEGA, Ibidem.

46. J. ORTEGA, Meditaciones del Quijote, I, 751-752.

47. J. ORTEGA, Sobre el santo, II, 25.

48. J. CONILL, op. cit., 94. 


\section{b) La superación del culturalismo}

A partir de los años veinte, Ortega plantea la superación definitiva del idealismo de la Modernidad y como consecuencia, describe una nueva relación entre el pensamiento político y la concepción de la filosofía y de la historia ${ }^{49}$. El encuentro con la fenomenología le permitió desembarazarse del neokantismo y del culturalismo y dar un paso en la dirección del que se convertirá en el impulso definitivo de su filosofía. En este sentido, matizará la pretendida sustitución de Dios por la cultura. Advertirá que también esta idolatría y totalitarismo de la cultura debería ser superada para poder, por fin, entender que no ha nacido el hombre para ser culto, sino la cultura para permitir al hombre $\operatorname{ser}^{50}$. La cultura como valor supremo ocupa el mismo lugar que en las culturas antiguas ocupaba la beatitud asumiendo los mismos atributos que aquello que sustituía y convirtiéndose en el nuevo Dios "al cristianismo sucede el culturalismo" 51 . "El culturalismo es un cristianismo sin Dios". Donde antes se decía Dios, Hegel dice "Idea", Kant "Primado de la Razón Práctica" o Cohen "Cultura". Pero de esta manera todos ellos suponían que el valor de la vida estaba más allá de la vida misma ${ }^{52}$.

Pero, aunque toma como punto de partida a Husserl, para Ortega no basta como exige el imperativo fenomenológico con ir "a las cosas mismas". El lema de Husserl lo traduce Ortega en "¡Salvémonos en el mundo!, ¡Salvémonos en las cosas!" "33. Ahora se trata de interpretar el sentido de la circunstancia y de una exigencia de transformación. "El acto específicamente cultural es el creador, aquel en el que extraemos el logos de algo que todavía era insignificante (i-lógico)" 54 .

En síntesis, la defensa de la razón vital consiste en afirmar que la razón es para la vida. La vida es la radical desorientación que re-

49. C. Flórez, Política y filosofía en Ortega. Teoría orteguiana de la modernidad, en M.T. López (ed.), Política y sociedad en Fosé Ortega y Gasset (Anthropos, Barcelona, 1997) 126.

50. J. Ortega, Sobre un Goethe bicentenario, VI, 555.

51. J. ORTEGA, Ibidem.

52. J. Ortega, El tema de nuestro tiempo, III, 600.

53. J. ORTEGA, ¿Qué es Filosofía?, VIII, 351.

54. J. Ortega, Meditaciones del Quijote, I, 756. 
quiere, para ser salvada, del estímulo originario del amor ${ }^{55}$, un grado superior de atención y sensibilidad con las circunstancias que parece surgir del reconocimiento del valor sagrado de la realidad entendida como posibilidad y limitación con la que el hombre, quiera o no, tiene que contar. El imperativo ético es fidelidad a la realidad, es decir, el paisaje como incitación y, sobre todo, como exigencia.

Desde esta consideración inicial, el giro que a partir de este momento se produce en su pensamiento pone en primer plano la filosofía de la vida. La antigua influencia de Nietzsche se matiza y clarifica con la influencia de Simmel $^{56}$ en la que se pueden encontrar incitadas resonancias, entre otras, de una defensa del primado de la vida en cuanto proceso creador, la vida como fuente última del valor al que referir todos los demás valores, el sentido deportivo de la vida y la doctrina del punto de vista. Ortega reconduce esta influencia según su propia concepción fenomenológica del yo y la circunstancia y la presencia de Scheler a la que no va a renunciar. Para Ortega lo característico del momento histórico es que al imperativo cultural entendido como la imposición de determinados valores externos a la vitalidad, le ha sucedido la exigencia nacida del reconocimiento del valor vital mismo: "la creación científica y artística, el heroísmo político y moral, la santidad religiosa son los sublimes resultados del deporte" ${ }^{57}$.

Lo interesante para nosotros es mostrar cómo desde este imperativo de salvación también se percibe en Ortega una abertura hacia la importancia de la religiosidad, en la dirección que ya esbozó anteriormente, al menos en cuatro sentidos: la búsqueda del fundamento no inmediatamente presente de la realidad, el valor vital de lo superfluo como plenamente humano, el reconocimiento del sentimiento y la capacidad estimativa como funciones de la razón y la abertura a la aportación del cristianismo como una perspectiva más.

En primer lugar, sensibilidad religiosa significa para Ortega compromiso con la riqueza, misterio e inagotabilidad de la realidad individual y colectiva: compromiso respetuoso de comprensión y de

55. J. Ortega, Las Atlántidas, III, 754.

56. N. ORRINGER, Ortega y sus fuentes germánicas (Gredos, Madrid, 1979) 293.

57. J. ORTEGA, El tema de nuestro tiempo, III, 608-609. 
acción. Ser religioso, en este sentido, consiste en reconocer que la realidad inmediata no es la realidad completa porque le faltaría el fundamento. Religiosidad significa búsqueda de la profundidad, una actitud que no renuncie a la ultimidad e integridad frente al doble peligro que representa el agnosticismo positivista, con su reduccionismo a lo empírico y el gnosticismo que se eleva y desinteresa de este mundo ${ }^{58}$. Por eso el agnóstico, para Ortega, renuncia a las cosas fundamentales y se mantiene con la mirada fija exclusivamente en este mundo. "Porque 'este mundo' es lo que queda del Universo cuando le hemos quitado todo lo fundamental; por tanto, un mundo sin fundamento" 59 . Hay épocas agnósticas que niegan la posibilidad de conocer aquello que no es una realidad inmediata y por ello dan la espalda a todo lo religioso. Sin embargo, Ortega reclama el reconocimiento de un "Dios laico" aspectos transcendentales de la vida. En consecuencia, entiende la emoción religiosa independiente y anterior a ser ateo o no serlo, un sentido de la religiosidad que no es la acepción generalmente tenida de relación con un Dios, y una interpretación de la verdad revelada, porque "Dios es también un asunto profano".

En segundo lugar, Ortega relaciona la emoción religiosa con la ruptura con la razón individualista y utilitaria del hombre burgués del siglo XIX, ruptura con la racionalidad técnica y calculadora y la mentalidad económica de la ética industrial. Frente a ésta, Ortega sitúa el entusiasmo, la vocación de aventura de quien asume el esfuerzo y el riesgo porque aspira a una altitud superior de exigencias y perfecciones. En consecuencia, lo valioso no nace de la utilidad, nace de la superfluidad de un esfuerzo desinteresado, nace del sentido deportivo y festivo de la vida. "Lo más necesario es lo superfluo" en este sentido, significaría deseo de trascendencia de uno mismo. La vida es proyecto, la esperanza no es solo una virtud, es la constitución misma de la vida entendida como abertura a la trascendencia.

58. P. Cerezo, La voluntad cit., 105.

59. J. ORTEGA, Dios a la vista, II, 607.

60. J. ORTEGA, Ibidem, 605.

61. J. ORTEGA, El origen deportivo del estado, II, 709. 
En tercer lugar, en ese camino de transformación del modelo mismo de razón, hay que aclarar que el imperativo de cultura y razón, para Ortega, no se refiere a una razón exclusivamente teórica. Para Ortega la cultura incluye, en clara herencia de Scheler, la educación del sentimiento y la capacidad estimativa de los valores. Los sentimientos modulan la vida psíquica. Nuestros conocimientos dependen de un sistema de preferencias que es más profundo y anterior al intelecto. Es un sistema de conciencia total, de manera que el conocimiento depende de la voluntad y el sentimiento, como éstos de aquel, que le hace afirmar que es un error suponer que los hechos de conciencia cognoscente son impermeables a la conciencia volitiva y sentimental ${ }^{62}$. Ortega habla de la necesidad de jerarquizar racionalmente los sentimientos y las emociones en la dirección de una "razón sentimental" aludiendo a Pascal ${ }^{63}$ y por eso es precisa una "educación sentimental" "64: "Al primer romanticismo de la liberación sigue este segundo, (...), cuyo lema es la selección y jerarquía”. En este sentido la religión tiene para Ortega un papel fundamental en la educación de los sentimientos puesto que hace referencia a una dimensión íntima de perspectiva personal que enriquece las infinitas posibilidades de emoción y de diferencia individual.

Lo mismo ocurre en cuanto a la estimación de los valores ${ }^{65}$. La ruptura con el idealismo con la que pretende superar la Modernidad, haría caer a Ortega en el relativismo moral si no se aceptara algún tipo de criterio normativo objetivo con el que poder orientar la acción. Para Ortega no todo vale por igual ${ }^{66}$. El descubrimiento de los valores ha sido para Ortega una de las conquistas fundamentales del siglo $\mathrm{XX}^{67}$, pero hay que advertir que al hablar de valores no nos referimos exclusivamente a valores morales, sino también de valores estéticos, culturales, políticos, económicos o vitales y religiosos. Los

62. J. ORTEGA, Guillermo Dilthey y la idea de la vida, VI, 247.

63. J. Ortega, Musicalia, II, 371.

64. J. ORTEGA, El Quijote en la escuela, II, 413-419; Corazón y cabeza, VI, 208.

65. A. PERIS, La ética de Ortega y Gasset: ilusión, autenticidad y valores, "Anales Valentinos" 64 (2006) 315-369.

66. I. SÁNCHEZ, Ortega y Gasset y la filosofía de los valores, "Revista de Estudios Orteguianos" 1 (2000) 163.

67. J. ORTEGA, Introducción a una estimativa, III, 531. 
valores son cualidades objetivas de las cosas que hay que aprender a descubrir, hay que aprender a estimar. Se refiere a valores como la audacia, la serenidad, el afán de aventuras, valores morales como la generosidad, la actitud amorosa ante la realidad o el valor de lo sagrado. La religiosidad es entonces, la actitud que consiste en ser sensible a la realidad y a unos principios, tomándolos como aquello que está más allá de lo mecánico, más allá de la voluntad o del acuerdo de los mismos hombres, descubrir una ley de objetividad, un criterio por encima de su individualidad.

Simultáneamente a estas afirmaciones, se percibe en Ortega un mayor aprecio por el cristianismo y su especificidad religiosa en la medida en que pueda ser una perspectiva entre otras, capaz de estimular la razón y generar pensamiento. Pero eso requiere una regeneración intelectual del catolicismo español.

Ortega había criticado la desmoralización y la falta de altura intelectual del catolicismo español ${ }^{68}$. El catolicismo español había sido, según piensa, una rémora para el perfeccionamiento nacional y opone a la visión de un catolicismo místico español el cristianismo que se está desarrollando en Europa. No podía aceptar ni entender que faltase en España un núcleo católico entusiasta capaz de buscar, a través del perfeccionamiento católico, el desarrollo de España ${ }^{69}$. Por eso criticaba un rasgo característico del gusto religioso español en las manifestaciones místicas y casi mágicas a las que con frecuencia se cae en el cristianismo popular, una fe inculta ${ }^{70}$ que no requiere de las justificaciones. En contraste con lo que estaba pasando en España, Ortega pensaba que el catolicismo europeo se podía estar convirtiendo en una fuerza de vanguardia, expresión de claridad científica y creadora: "el alma europea se halla próxima a una nueva experiencia de Dios, a nuevas averiguaciones sobre esa realidad, la más importante de todas" pero que el camino de esa nueva visión religiosa no es el éxtasis místico irracional que es característico en España. Cualquier teología acerca más a las nociones de la divinidad

68. A. Martín, Ortega cit., 85.

69. J. ORTEGA, La forma como método histórico, IV, 125-126.

70. J. ORTEGa, Sobre el vuelo de las aves anilladas, IV, 238. 
que una aparición de éxtasis mística ${ }^{71}$. De esta manera se abriría el camino de una religión capaz de entrar en diálogo con la ciencia y el pensamiento, capaz de superar la antinomia entre dogmatismo y ciencia. Una "fe que busca entender" "La fe que siente su propia plenitud en forma de enorme sed de intelecto, no de petulante satisfacción propia... No es una fe holgazana" 72.

Ortega aplaude y propone un reto siempre presente que consistiría en hacer inteligibles las verdades que contiene la tradición católica, repensar las tesis católicas a fin de "aproximarlas a la mente actual (...) para mostrar "su fertilidad en tal o cual cuestión”. Y pone como ejemplo el trabajo que están haciendo católicos alemanes como Scheler, Guardini o Przywara que dice:

...se han tomado el trabajo de recrear una sensibilidad católica partiendo del alma actual. No se trata de renovar el catolicismo en su cuerpo dogmático ("modernismo"), sino de renovar el camino entre la mente y los dogmas. De este modo han conseguido, sin pérdida alguna del tesoro tradicional, alumbrar en nuestro propio fondo una predisposición católica, cuya latente vena desconocíamos. Una obra así es propia de auténticos pensadores ${ }^{73}$.

Esta es la propuesta y el lugar último del cristianismo en la sociedad: mostrar la vigencia de unas enseñanzas que han formado parte de la humanidad y su desarrollo desde hace siglos pero que no son comprensibles para el hombre del mundo actual y afrontar la tarea de traducir su aportación y su riqueza a la nueva sensibilidad ${ }^{74}$.

Ortega profundiza en este análisis ${ }^{75}$. El cristianismo según piensa Ortega, supuso la aparición de una nueva experiencia del mundo y de la vida. Pero al tener que expresarse con las categorías

71. J. ORTEGa, Defensa del teólogo frente al mistico, V, 727 y ss.

72. J. ORTEGa, Espiritu de la letra, IV, 163.

73. Ibidem.

74. J. J. GARRIDO, op. cit., 239.

75. J. J. GARRIDO, op. cit., 243-244. 
de la filosofía griega de Platón y Aristóteles extrañas ${ }^{76}$ y ajenas al cristianismo, hicieron que la interpretación aristotélica del cristianismo, por ejemplo en Santo Tomás, se convirtiera en una desfiguración $^{77}$. Por eso se trataría de superar esa manera ontológica de pensar la experiencia religiosa ${ }^{78}$ para recuperar la que hubiera sido la auténtica y original filosofía cristiana. No se trata de traducir a términos racionales una verdad secularizándola, "No se trata, conste, de que el hombre, una vez que Dios se ha revelado en la fe, pretenda reconstruir todo el contenido de la fe mediante puro razonamiento humano, logrado lo cual podría, claro está, prescindir de la fe"79. Se trata de que la inteligencia debe trabajar la fe, es decir, completar esa racionalidad incluyendo en ella una dimensión religiosa espiritual, que no tiene porqué ser irracional. Pero hacerlo sin desvincularlas de la experiencia religiosa, porque quizá la fe no tiene porqué ser compartida, pero la religiosidad sí puede serlo.

En este sentido, el cristianismo se convertiría en una perspectiva de interpretación específicamente religiosa complementaria con otras, como la que ofrece la ciencia, pero una perspectiva que hay que tomarse el trabajo de pensar. Esta tarea requeriría superar una concepción excluyente del cristianismo para tomar la interpretación específicamente cristiana como una propuesta realizada desde una perspectiva entre otras posibles, sin tener por ello que caer en el relativismo por el que la verdad no existe. Las distintas perspectivas no tendrían porqué entenderse desde la competencia, sino desde la complementariedad y el enriquecimiento mutuo. La cultura y la filosofía, tomadas como instrumentos de búsqueda y de comprensión del sentido de la realidad y su fundamento, necesitan la dimensión religiosa como de un elemento y una perspectiva imprescindible. Los distintos planos no deben mezclarse. Cuando se mezclan los planos de la religión, la ciencia, la moral o la política y tendemos a proyec-

76. J. ORTegA, La idea de principio en Leibniz y la evolución de la teoría deductiva, IX, 1022.

77. J. ORTEGA, En torno a Galileo, VI, 441 y VI, 472-473.

78. J. ORTEGA, La idea de principio en Leibniz y la evolución de la teoría deductiva, IX, 1068-1069.

79. J. ORTEGA, En torno a Galileo, VI, 474. 
tar todo el universo desde un mismo plano, en vez de respetar sus múltiples dimensiones, entonces una instancia suprime a todas las demás y el resultado último se empobrece ${ }^{80}$. La Iglesia se convertiría en institución de cultura en sentido amplio, un gran instrumento de educación del género humano.

\section{c) La religiosidad en el surgimiento de la razón histórica}

El final de los años veinte y el comienzo de los treinta suponen para Ortega años de plenitud. Tiene la conciencia de haber alcanzado la cima de su pensamiento al profundizar en las fórmulas iniciales en la dirección de la razón histórica ${ }^{81}$. La concepción de vida del hombre como lucha con su íntimo destino y la estructura de la historia desde la articulación y crisis de las creencias, le permiten formular la razón histórica como una propuesta definitiva de superación de la Modernidad.

La nueva perspectiva consiste en la consideración de la historicidad de la vida, es decir, la visión de la realidad del presente como consecuencia del pasado y orientación para el futuro; y a la vez, la conciencia de la razón histórica como concepción sistemática de la historia y del sentido de la vida. La misma exigencia de realización efectiva en el futuro obliga a tener en cuenta el arsenal de los instrumentos, los medios que el hombre conserva del pasado. Por eso el hombre es constitutivamente histórico, porque en cada presente se acumulan y superponen una síntesis de visiones del mundo de las generaciones anteriores.

La religiosidad se va a presentar aquí profundizando en dos principios: la fidelidad a la realidad y a la historia de la que emanan como creencias los referentes y principios que nos constituyen, y la determinación de los fines últimos, coherentes con esa historia, a los que dirigirse tanto socialmente como personalmente en la idea de vocación.

80. J. ORTEga, Para la cultura del amor, II, 277.

81. J. MARÍAS, Las trayectorias (Alianza, Madrid, 1983) 339. 
La razón de la Modernidad habría producido, según lo piensa Ortega, un vacío. El triunfo de la razón físico-matemática y de la libertad individual habrían degenerado en el racionalismo como ideología, que se impone como eficiencia positivista, y en una forma de individualismo aislado, absolutización del sujeto preocupado sólo de sí mismo, que radicalizaría la idea de libertad tomándola como derecho a no someterse a ninguna autoridad ${ }^{82}$. La consecuencia es que se impone la razón subjetiva que se apoya en otras subjetividades hasta convertirse en masa, sin que ello signifique reconocer una instancia trascendental de verdad y sin dejar por ello de estar encerrada en sí misma. De esta manera, el mismo triunfo de la cultura de la Modernidad produciría su contradicción en la civilización del hombre masa, cuya carencia de referentes absolutos le condena a ser víctima de sí misma, de su propio poder.

Y aquí surge una vez más la religiosidad en la necesidad de acatar ciertas posiciones intelectuales últimas que son resultados de la historia compartida y desde las que ha de surgir el proyecto de futuro, por ejemplo: la voluntad de buscar la verdad y no solo una negociación o apelar a una instancia a la que supeditarse para no caer en la barbarie o la exigencia de actuar conforme a la razón, en contra, por ejemplo, del muy actual derecho a no tener razón ${ }^{83}$. Como en otros momentos vimos, la verdadera cultura se sustenta en la emoción religiosa entendida como la disciplina interna de reconocimiento y respeto escrupuloso hacia ciertas ideas que están por encima del sujeto: una tarea, un proyecto, unos principios o unos valores descubiertos y asumidos. Cuando el hombre cree en algo, en una realidad, en el legado de la tradición y de la historia, en un proyecto valioso, en una idea, en un principio trascendente al que servir, deja de ser negligente para ser religente (religiosus) esto es: escrupuloso, disciplinado ${ }^{84}$.

Cuando esa realidad, única cosa que disciplina y limita a los hombres de manera automática y desde dentro de ellos mis-

82. P. CEREZO, La voluntad cit., 70.

83. J. ORTEGa, Rebelión de las masas, IV, 417.

84. J. OrTega, Historia como sistema y Del Imperio Romano, VI, 95. 
mos, se desvanece por volatilización de la creencia, quedan solo pasiones en el ámbito social [...entonces] Cada cual proclama lo que le dicta su interés o su capricho ${ }^{85}$.

Por esta razón, la religiosidad se presenta en la dinámica de las creencias, característica de la razón histórica. La sociedad se compone de un sistema de usos consolidados a lo largo de la historia: un conjunto de puntos de referencia firmes que hacen posible la convivencia. Entre estos usos se encuentran las creencias ${ }^{86}$. "Siempre, irremisiblemente, en cada instante, nos hallamos con determinadas convicciones radicales sobre lo que son las cosas y nosotros entre ellas" ${ }^{87}$. Toda interpretación se nutre de otras precedentes, cada idea se sustenta en un substrato de ciertas creencias que en última instancia son inexpresables. Sin que esto suponga caer en el tradicionalismo de someterse a la herencia inmóvil del pasado.

Se trataba de encontrar una síntesis entre razón histórica y proyecto de futuro. Por eso, por último, encontramos una referencia religiosa en la necesidad de fijar los fines últimos a los que dedicar la $v$ ida $^{88}$. Lo expresa con especial claridad en relación a la técnica. La ciencia moderna está unida a la técnica porque la misma condición humana es fabricación de sí misma. Pero lo característico del momento es que ha llegado a una altura en la que, en contra de lo que ha ocurrido en cualquier otro momento de la historia, el hombre tiene conciencia de tener posibilidades ilimitadas. Lo paradójico es que de puro poder ser cualquier cosa pero sin referentes, se siente vacía, no es nada. Por eso no se debe olvidar que la técnica no es lo primero, a la técnica le es prefijada la finalidad. Esa capacidad de ejecutar está siempre al servicio de un programa vital que habrá de crear una instancia anterior a la técnica misma y que en cada caso podrá ser el filósofo, el religioso o el político ${ }^{89}$. Es decir, la técnica habla de medios, pero los fines deben surgir de una racionalidad sensible a conformar una

85. J. ORTEGA, Ibidem, VI, 93.

86. J. ORTEGA, Ideas y creencias, V, 671.

87. J. ORTEGA, En torno a Galileo, VI, 380.

88. A. Moreno, op. cit., 483.

89. J. OrTega, Meditación de la técnica, V, 575. 
orientación de sentido que debe incluir aspectos como creencias y expectativas compartidas.

En todas estas caracterizaciones religiosas subyace, sin embargo, una idea de inspiración profundamente religiosa y cristiana, el imperativo de individualidad y vocación de llegar a ser sí mismo ${ }^{90}$. "Vida significa la inexorable forzosidad de realizar el proyecto de existencia que cada cual es" ${ }^{\text {. }}$. El hombre que acepta su destino, se entrega incondicionalmente a él como una instancia superior a la que servir, es su razón de ser. "Nuestro yo es en cada instante lo que sentimos tener que ser" ${ }^{\prime 2}$. Es una posibilidad de excelencia, por tanto, no necesaria, es la realización de un ideal posible y ajustado a la realidad en cuanto se presenta como la resolución de la problematicidad de la situación concreta. La posibilidad imaginada se convierte así, en una "posibilidad necesaria"93.

\section{LA INTEGRACIÓN DE LA RELIGIOSIDAD EN EL ESTADO LAICO}

Esta concepción de la religiosidad en la que la razón se hace compatible con la religiosidad es la que puede y debe encontrar espacio en una sociedad plural.

La defensa del estado laico en Ortega, es consecuencia de uno de sus principios políticos junto al liberalismo: la nacionalización. Nacionalización consiste en la insistencia de unir a los ciudadanos en proyectos, valores y rasgos de identidad compartidos superando, de este modo, los particularismos excluyentes. En ese contexto se afirmaba en un documento de la Agrupación al Servicio de la República: "Laico no significa ateo, sino simplemente nacional" 4 .

El gran problema político español había sido siempre, desde la visión de Ortega, el "morbo disociador", es decir, la actitud excluyente

90. J. Ortega, Misión del bibliotecario, V, 350.

91. J. Ortega, Pidiendo un Goethe desde dentro, V, 124.

92. J. Ortega, Sobre la leyenda de Goya, IX, 806.

93. J. ORTEGA, Ibidem, IX, 808.

94. "Circular" de la Agrupación al Servicio de la República, V, 105. Aunque los textos de la ASR son colectivos y por tanto no se puede garantizar la responsabilidad exclusiva de sus ideas, en este caso el manuscrito es de Ortega. 
de los distintos grupos atentos únicamente a su interés o a su visión particular. Lo característico de este análisis es que el particularismo no se reduce a los nacionalismos separatistas, sino que se extiende a otras actuaciones que incluyen la misma imposición centralista del poder establecido, las actitudes tanto de grupos de empresarios como de trabajadores y, en muchas ocasiones, también la misma actitud de la Iglesia. La esencia de este fenómeno es que cada grupo deja de sentirse como parte y quiere ser el todo. El particularismo, en su base psicológica, según explica, entraña una postura personal irreductible, en la que el prójimo carece de valor ante la exagerada valoración del propio yo o la infravaloración del otro. El gran mal de los españoles era la soberbia ${ }^{95}$ : el solipsismo estimativo. Por eso el propósito había de ser el contrario: contar con los demás, aunar fuerzas y excluir la exclusión $^{96}$.

El Estado nacional se había de construir siempre con capacidad de integración de todos los ciudadanos; en consecuencia, no podía ser confesional, porque por su propia naturaleza la confesionalidad supondría excluir al no creyente. Por eso entre las críticas a la Iglesia se incluye, sobre todo, la tendencia de ésta al particularismo. La tendencia a plantear que la verdad cristiana es la única, tendría como consecuencia la intrínseca dificultad de aceptar el pluralismo. La Iglesia, que comienza siendo un instrumento de integración, se convertiría de esta manera, especialmente en España, en una fuerza disgregadora. Además, según piensa Ortega, la presencia real del cristianismo en las creencias compartidas era cada vez menor. El clero había dejado de sostener la autoridad espiritual y la capacidad de liderar socialmente y sin embargo parecía querer mostrarse públicamente como si nada hubiera cambiado. En realidad, se recurre a la influencia política cuando el poder social se ha perdido; "y de paso, —añade Ortega-, la Iglesia, viviendo en falso, y esto es lo triste, viviendo en falso se desmoralizaba ella misma gravemente" ${ }^{97}$.

95. J. ORTEGa, Para una topografía de la soberbia española, V, 178.

96. J. ORTEGA, España invertebrada, III, 471.

97. J. ORTEGA, El poder social, IV, 93-94. 
La separación de la Iglesia y el Estado suponía que cualquier pretensión o sospecha de predominio de la opinión de la Iglesia en el terreno político, de privilegio en el sostenimiento económico o de cualquier tipo de favor o preferencia social, fuera el que fuera, debía ser siempre interpretado como contrario al principio de igualdad y unidad política y sería, por tanto, previsiblemente causa de discordias que darían pie a la crítica y el revanchismo. En consecuencia, el Estado debía ser laico.

El Estado tiene que ser perfectamente y rigorosamente laico; tal vez ha tenido que detenerse en esto y no hacer ningún gesto de agresión. Yo, señores, no soy católico (...); pero no estoy dispuesto a dejarme imponer por mascarones de proa de un arcaico anticlericalismo ${ }^{98}$.

Y en otro lugar: "yo, que no soy católico, no tengo un solo pelo de anticlerical, (...) porque hoy anticlerical es solo el que no puede ser otra cosa, es una manifestación de íntima incultura, es decir de inactualidad, como otra cualquiera; por ejemplo como ser clerical"99. Según piensa Ortega, Roma y la mayor parte de los católicos reconocían la necesidad de ese estricto laicismo.

Para quienes pretendían un anticlericalismo radical que no solo buscaba la secularización del Estado, sino la eliminación de la influencia de la Iglesia en la sociedad, la cuestión del laicismo del Estado era especialmente importante en el terreno de la educación. Una postura que se justificaba por la supuesta peligrosidad de las religiones para la salud democrática y que postulaba su reducción a una manifestación íntima, no pública. Para Ortega la educación, en la medida en que había de ser una exigencia al Estado para poner en condiciones de autonomía a todos los hombres, había de ser un servicio público y en consecuencia, había de ser laica en el sentido etimológico original: del pueblo por contraposición a un grupo concreto. La escuela laica sería la única que podía ser para todos porque

98. J. ORTEGa, Rectificación de la República, IV, 847.

99. J. ORTEGA, En torno a Galileo, VI, 496. 
no disociaría ni rechazaría otras creencias e ideas ${ }^{100}$. Sin embargo, en la línea de lo que venimos explicando, habría que advertir que escuela laica no significa irreligiosa, porque laica no es lo contrario de religiosa, sino lo opuesto a eclesiástica. Para Ortega no cabe dentro de la pedagogía científica la exclusión del elemento religioso, siempre, eso sí, que lo religioso fuera tratado como una cuestión o con un enfoque científico ${ }^{101}$.

A la altura de 1953, para un Ortega maduro muy posterior a las preocupaciones de la confrontación civil española y más cercano a la realidad europea de posguerra, es evidente que la realidad social que hay que tener en cuenta al diseñar la política del futuro es precisamente la disociación del cuerpo colectivo en distintas filosofías y perspectivas ante la vida. Es decir, con más claridad, el problema que se plantea en la política es la diversidad cultural. Lo que en otro tiempo servía de criterio de unificación como era la fe en la cultura, la adhesión a una moral común o la fidelidad a la patria se ha perdido definitivamente ${ }^{102}$. En consecuencia, la nueva sociedad no puede ser monolítica, no vale ya ninguna visión excluyente ni con pretensión definitiva.

\section{CONCLUSIONES}

Quizá con esto podríamos responder a nuestra cuestión sobre qué puede aportar la religión en un Estado laico. Una religión debe aportar ante todo auténtica religiosidad. Una religión no es un código ético, o al menos no de modo primario, ni una fuente de inspiración de orientaciones políticas. La religiosidad representa una perspectiva y una sensibilidad especiales que completan la necesidad de orientación y sentido que ofrece la cultura. La religiosidad es una dimensión esencial de ese cultivo, que expresa una condición anterior a la religión revelada misma y que es compatible y ocupa un espacio a considerar en la estricta racionalidad filosófica.

100. J. ORTEGA, La pedagogía social como programa político, II,100.

101. J. ORtega, Catecismo para la lectura de una carta, I, 330.

102. J. OrTega, Apuntes sobre una educación para el futuro, X, 386. 
Según hemos visto, la religiosidad en Ortega puede expresar aspectos distintos. La necesidad de buscar un horizonte de sentido y fundamento último desde una actitud contemplativa que no se conforma con una visión superficial de las cosas limitada a lo estrictamente material. Tomar la vida como compromiso con la realidad, compromiso de verdad y compromiso de salvación más allá de la urgencia apresurada, más allá del beneficio de lo útil o lo rentable y que puede oponer a la dictadura del tecnicismo y de la eficacia y la eficiencia económica un proyecto humanizador. Religiosidad expresa la concepción de la vida como voluntad de alcanzar lo innecesario, la aspiración magnánima a ir más allá de lo exigible o lo correcto. Religiosidad se refiere además a la educación sentimental que supera una concepción de la razón teórica, abierta a estimar ciertos valores que disciplinan porque son tomados como criterios que están por encima de la voluntad o el arbitrio de los sujetos. Y finalmente significa entender la libertad como la respuesta a una exigencia que nace del encuentro con la historia a través de la misma realidad compartida y de la que nacen los mismos proyectos de futuro. Esta perspectiva podría guardar relación con la razón sentiente de Zubiri o la razón poética de Zambrano, aunque su tratamiento supera las posibilidades de este artículo.

Pero, sobre todo, sería necesaria una nueva presencia de lo religioso en diálogo con el mundo actual. Hacer presente de manera comprensible y racional el significado de las enseñanzas del cristianismo. Repensar la originalidad de la experiencia cristiana de entender la vida y la relación entre los hombres y hacerse explicar ante el mundo no cristiano. De esta manera se podría superar definitivamente la concepción que reducía la religiosidad a un ámbito privado por irracional haciendo posible ensayar una razón que incluyera una perspectiva espiritual o religiosa.

La conclusión es que Ortega fue tremendamente respetuoso con la religión, quizá asumiendo que, aunque personalmente no participaba de una mirada que le permitiera alcanzar otras trascendencias, el papel que la religión había tenido y que podía llegar a tener como dinamizadora en la construcción social era suficientemente importante para tenerla en consideración. Es decir, se trataba de de- 
fender un Estado laico, independiente, neutro, que no toma partido, pero que a la vez era capaz de reconocer que lo religioso cumple una función social importante. La defensa del Estado laico estaría entonces tan alejada del Estado confesional como del anticlerical, pero no es mero vacío indiferente, ni ignorancia frente a lo religioso ${ }^{103}$.

103. Este trabajo se enmarca en el Proyecto de Investigación "Crisis y relectura del liberalismo en el período de entreguerras (1920-1938): las aportaciones de Walter Lippmann y José Ortega y Gasset", financiado por el Ministerio de Economía y Competitividad del Gobierno de España (Ref: FFI2013-42443-R). 
